\title{
TERRITORIALIDADE E DEMARCAÇÃO DE TERRAS INDÍGENAS NO TOCANTINS: O HISTÓRICO DOS KARAJÁ DO NORTE
}

\author{
Daíse Alves (UFT - daiseadv@ hotmail.com) \\ Martha Victor Vieira (UFT - martha.victor@uft.edu.br)
}

RESUMO: Este artigo pretende analisar a demarcação da Terra Indígena Xambioá, localizada em Santa Fé do Araguaia, Estado do Tocantins. Nosso objetivo é demonstrar como o governo brasileiro, por meio das políticas indigenistas, ignora a territorialidade indígena e dificulta a regularização das suas terras, beneficiando os interesses daqueles agentes que pretendem explorar economicamente os espaços ocupados por esses povos originários.

PALAVRAS-CHAVE: Karajá do Norte; Territorialidade; Estado do Tocantins.

\begin{abstract}
This article intends to analyze the demarcation of the Xambioá Indigenous Land, located in Santa Fé do Araguaia, State of Tocantins. Our objective is to demonstrate how the Brazilian government, through indigenous policies, ignores indigenous territoriality and makes it difficult to regularize these lands, benefiting the interests of those agents who intend to economically exploit the spaces occupied by these original peoples.
\end{abstract}

KEYWORDS: Northern Karaja; Territoriality; State of Tocantins.

\section{INTRODUÇÃO}

O Estado do Tocantins foi criado em 1988, no governo do presidente José Sarney. Nesse Estado, de acordo com dados da FUNAI (2016), existe uma grande diversidade de etnias indígenas espalhadas pelo seu extenso território. As múltiplas comunidades indígenas estão localizadas em vários municípios e, em geral, com suas terras demarcadas em local específico. As etnias estão distribuídas em Apinayé, Xerente, Javaé, Karajá, Krahô-kanela, Krahô, Ava-Canoeiro, Tapirapé, Guarani. Entre as etnias dominantes no Tocantins estão os Karajá, Javaé, Xerente, Apinajé, Krahô, Avá-Canoeiro. 


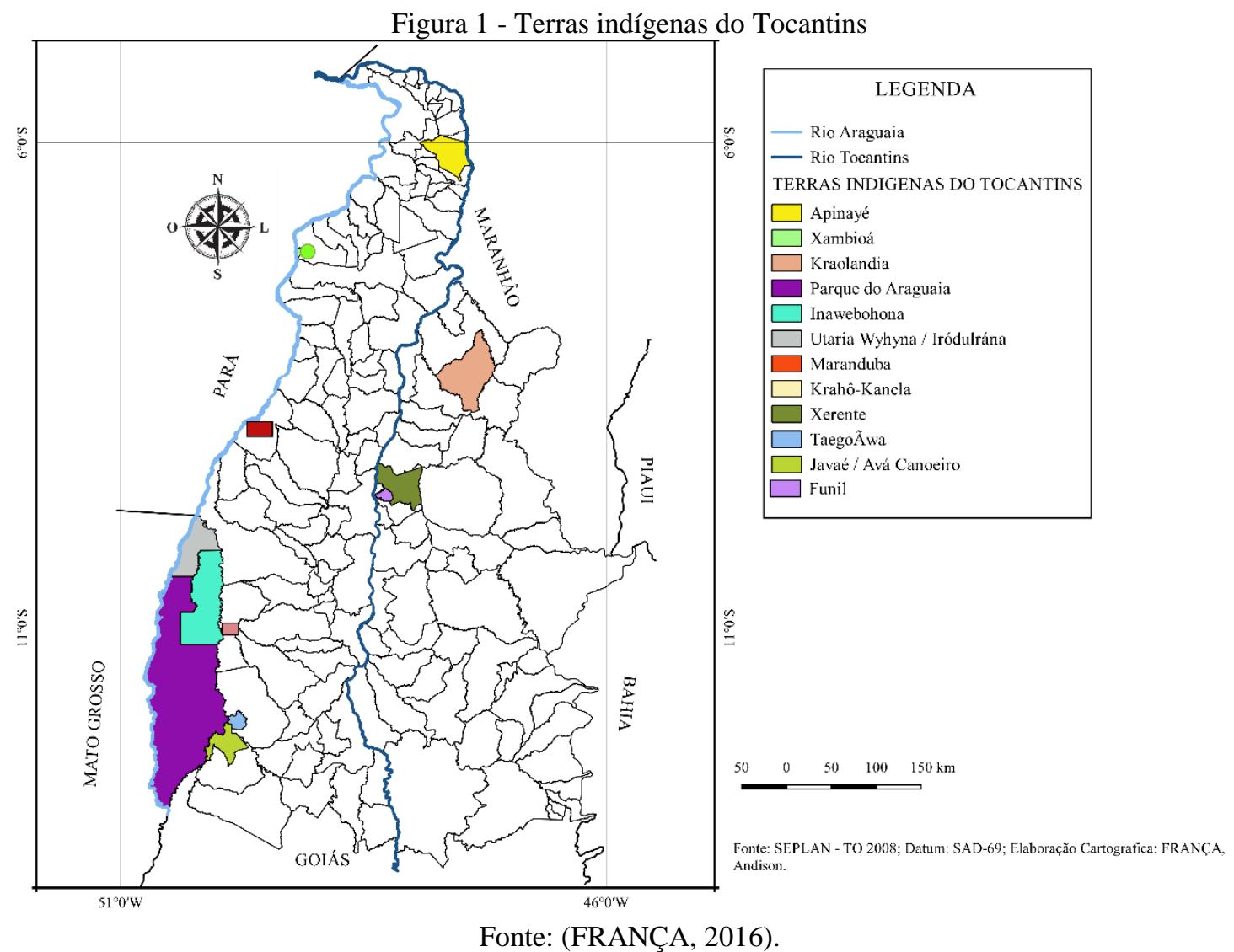

As terras indígenas, no Tocantins, estão distribuídas em doze repartições: Apinayé, Xambioá, Kraolândia, Parque do Araguaia, Inawebohona, Utaria Wyhyna (IròduIràna), Krahó-Kanela, Xerente, TaegoAwã, Javaé (Avá-Canoeiro), Funil, e, entre os Estados de Tocantins e Pará, Maranduba.

Dentre as doze terras indígenas existentes nesse Estado verifica-se, contudo, que algumas estão oficialmente demarcadas e outras estão em estudo para processo demarcatório (FUNAI, 2017), conforme se demonstra na tabela abaixo.

Tabela 1 - Relação das terras indígenas no Tocantins

\begin{tabular}{ccccc}
\hline $\begin{array}{c}\text { Terra } \\
\text { Indígena }\end{array}$ & $\begin{array}{c}\text { Localizaç } \\
\text { ão }\end{array}$ & Área (ha) & Etnia & $\begin{array}{c}\text { Situação } \\
\text { Legal }\end{array}$ \\
\hline Apinayé & Cachoeirin & 141.904, & Apina & $\begin{array}{l}\text { Regulariz } \\
\text { ada } \\
\end{array}$ \\
& ha, Itaguatins, & 2092 & \\
Maurilândia do & & & \\
& Tocantins, São & & \\
& Bento do & & \\
& Tocantins, & & \\
&
\end{tabular}




\begin{tabular}{|c|c|c|c|c|}
\hline & Tocantinopólis. & & & \\
\hline Xambioá & $\begin{array}{l}\text { Santa Fé } \\
\text { do Araguaia }\end{array}$ & $\begin{array}{l}3.326,350 \\
2\end{array}$ & $\begin{array}{l}\text { Guara } \\
\text { ni e Karajá }\end{array}$ & $\begin{array}{l}\text { Regulariz } \\
\text { ada }\end{array}$ \\
\hline $\begin{array}{l}\text { Kraolândi } \\
\text { a }\end{array}$ & $\begin{array}{l}\text { Itacajá e } \\
\text { Goiatins }\end{array}$ & $\begin{array}{l}302.533, \\
3971\end{array}$ & Krahô, & $\begin{array}{l}\text { Regulariz } \\
\text { ada }\end{array}$ \\
\hline $\begin{array}{l}\text { Parque do } \\
\text { Araguaia }\end{array}$ & $\begin{array}{l}\text { Formoso } \\
\text { do Araguaia, } \\
\text { Lagoa da } \\
\text { Confusão e } \\
\text { Pium. }\end{array}$ & $\begin{array}{r}1.358 . \\
499,4784\end{array}$ & $\begin{array}{l}\text { Avá- } \\
\text { Canoeiro, } \\
\text { Javaé, Karajá } \\
\text { e Tapirapé }\end{array}$ & $\begin{array}{l}\text { Regulariz } \\
\text { ada }\end{array}$ \\
\hline $\begin{array}{l}\text { Inaweboh } \\
\text { ona }\end{array}$ & $\begin{array}{l}\text { Pium e } \\
\text { Lagoa da } \\
\text { Confusão }\end{array}$ & $\begin{array}{l}377.113, \\
5744\end{array}$ & $\begin{array}{l}\text { Javaé } \\
\text { e Karajá }\end{array}$ & $\begin{array}{l}\text { Regulariz } \\
\text { ada }\end{array}$ \\
\hline $\begin{array}{l}\text { Utaria } \\
\text { Wyhynal } \\
\text { IròduIràna }\end{array}$ & Pium & $\begin{array}{l}177.466, \\
0000\end{array}$ & $\begin{array}{l}\text { Javaé } \\
\text { e Karajá }\end{array}$ & Declarada \\
\hline $\begin{array}{l}\text { Marandub } \\
\text { a }\end{array}$ & $\begin{array}{c}\text { Araguace } \\
\text { ma-TO e Santa } \\
\text { Maria das } \\
\text { Barreiras-PA }\end{array}$ & 375,1538 & Karajá & $\begin{array}{l}\text { Regulariz } \\
\text { ada }\end{array}$ \\
\hline $\begin{array}{l}\text { Krahó- } \\
\text { Kanela }\end{array}$ & $\begin{array}{l}\text { Lagoa da } \\
\text { Confusão }\end{array}$ & $\begin{array}{l}7.612, \\
7653\end{array}$ & $\begin{array}{l}\text { Krahô- } \\
\text { Kanela }\end{array}$ & $\begin{array}{l}\text { Regulariz } \\
\text { ada na } \\
\text { modalidade de } \\
\text { reserva indígena }\end{array}$ \\
\hline Xerente & Tocantínia & $\begin{array}{l}167.542,1 \\
058\end{array}$ & $\begin{array}{l}\text { Xerent } \\
\mathrm{e}\end{array}$ & $\begin{array}{l}\text { Regulariz } \\
\text { ada }\end{array}$ \\
\hline TaegoAwã & $\begin{array}{l}\text { Formoso } \\
\text { do Araguaia }\end{array}$ & $\begin{array}{l}29.000 \\
0000\end{array}$ & $\begin{array}{l}\text { Avá- } \\
\text { Canoeiro }\end{array}$ & Declarada \\
\hline $\begin{array}{l}\text { Javaé/Avá } \\
\text {-Canoeiro }\end{array}$ & $\begin{array}{l}\text { Formoso } \\
\text { do Araguaia e } \\
\text { Sandolândia }\end{array}$ & $\begin{array}{l}\text { Área ainda } \\
\text { a ser delimitada }\end{array}$ & Javaé & Em estudo \\
\hline Funil & Tocantínea & $\begin{array}{l}15.703, \\
7974\end{array}$ & $\begin{array}{l}\text { Xerent } \\
\text { es }\end{array}$ & $\begin{array}{l}\text { Regulariz } \\
\text { ada }\end{array}$ \\
\hline
\end{tabular}

Fonte: (FUNAI, 2017).

Como se pode constatar, nove terras estão devidamente demarcadas com processo de demarcação concluído, sendo um parque e uma reserva indígena. As terras Javaé/AváCanoeiro, TaegoAwã, Utaria Wyhyna\IròduIràna não tiveram seus processos de demarcação concluídos pela FUNAI, aguardando diversos outros procedimentos. A Terra Indígena Javaé/Avá-Canoeiro está em fase de estudo antropológico, histórico, fundiário, cartográfico e ambiental, que fundamentam a identificação. Por sua vez, as Terras Indígenas Utaria Wyhynal IròduIràna e TaegoAwã encontram-se declaradas, isto é, com procedimento de demarcação física do território, através de fixação de marcos e georreferenciamento.

Entre as terras demarcadas nos chama a atenção a Terra indígena Xambioá, localizada no município de Santa Fé do Araguaia, cujo processo de demarcação iniciou no período do 
SPI (Serviço de Proteção ao Índio), mas que só foi concluído nos anos de 1990. Esse processo demarcatório constitui um bom exemplo das dificuldades e morosidade do processo de regularização das terras indígenas no Brasil.

\section{OS KARAJÁ DO NORTE}

O município de Santa Fé do Araguaia foi criado pela Lei Estadual $n^{\circ}$ 251, de 20 de fevereiro de 1991, sendo desmembrado de Araguaína, localizada no Norte do Tocantins. Estima-se que a população desse município, em 2016, é de 7.318 habitantes, com área territorial de 1.678,091 km2 (IBGE, 2010). No município, à beira do Rio Araguaia, está localizada a Terra Indígena Xambioá, ocupada pela etnia Karajá e Guarani. Essa Terra Indígena possui uma área de 3.326,3502 ha e população total indígena de 331 pessoas, sendo que 292 se declaram indígenas, 33 consideram-se indígenas e 6 não se declaram e consideram-se indígena, de acordo com a pesquisa do Censo IBGE de 2010 (FUNAI, 2016).

O termo Xambioá vem de ixybiowa, que significa "amigo do povo", que era o "nome de uma aldeia que existiu na foz do rio de mesmo nome" (ALBUQUERQUE, 2013: 145), onde se supõe que foi aplicado o nome a todos seus habitantes e, posteriormente, aos Karajá do Norte. A antropóloga Melo (1996: 74), no histórico feito em 1996 para o processo de demarcação dessa Terra Indígena, afirma que:

Xambioá é uma denominação derivada da própria língua Karajá, ixÿ - que quer dizer povo e biawa - amigo, para outros estudiosos o termo significa amigos de porcos. São, ainda denominados como iraru madadu, ou gente de baixo, sendo, também, conhecidos como "Karajá do Norte", por habitarem a parte setentrional do rio Araguaia. (MELO, 1996: 74)

Em relação ao termo Karajá, por sua vez, parece haver uma divergência entre os estudiosos. Jacobs (2000) afirma que: “Karajá (nome de origem tupi) se autodenominam berohykÿ mahãdu (gente do rio grande), em oposição aos Javaé, aos quais eles se referem como ixÿju mahãdidu (gente do mato) ou bero biawa (amigos do rio)” (MELO, 1996: 12). Já Melo (1996) aponta que Karajá teria sua origem na língua Guarani, "significando macaco grande ou guariba, ainda são denominados como iboo mahadu, gente de cima ou do montante". E, Javaé, outra denominação dos Karajá (Karajá-Javaé) tem a significação desconhecida, são "denominados como ituamahadu, povo do meio" (MELO, 1996: 74). 
Segundo Toral (1992), os Karaja se autodenominam "Karajá do Norte" e têm uma rejeição ao uso do termo "Xambioá", preferindo o termo karajá pois valoriza a sua condição de indígena.

Sua atual autodenominação não os coloca como um grupo cultural e linguisticamente divergente em relação aos demais Karajá (e Javaé). Antes, enfatiza sua ligação a um estoque comum, cultural e linguisticamente definido e que, ao contrário deles mesmos, não enfrentou um forte processo deculturativo, em função de uma brutal perda de população e de casamentos inter-étnicos. (TORAL, 1992: 33).

A Terra Indígena Xambioá é considerada tradicionalmente ocupada pelos Karajá e Guarani. Essa aldeia teria sido fundada em 1872 e dirigida pelo capuchinho frei Savino de Rimini e, em 1877, foi descrita como "a mais afastada da população civilizada" estando "no centro de tribos ainda bravias", motivo pelo qual foi encaminhada uma força militar de dez soldados para guardar a missão. Consta-se que, em 1886, seiscentos índios viviam na aldeia e trabalhavam fornecendo madeira para barcos a vapor. (KARASCH, 1992: 409).

Os Karajá, atualmente, ocupam as margens do Rio Araguaia, mas "no final do séc. XVI e início do XVII, as expedições paulistas de captura de escravos já encontraram os Karajá estabelecidos nas proximidades da foz do rio das Mortes" (TORAL, 1992: 41). No século XIX, os Karajá eram conhecidos por terem as maiores, mais populosas e mais prósperas aldeias. Poucos estudos, porém, são feitos sobre a origem do grupo. Na visão de Toral, "Somente no início do séc. XX os registros passam a discriminar o nome de suas aldeias, boa parte delas ainda existentes nos dias de hoje" (TORAL, 1992: 06).

A aldeia Xambioá, segundo Albuquerque (2013), é composta por Karajá do Norte em sua maioria, bem como pelos Mbya-Guarani, que residem nela devido aos casamentos interétnicos entre esses dois grupos, ocorridos na década de 1980. Os Karajá-Norte tiveram contatos com diversos grupos indígenas ao longo da sua história, entre os quais constam: os Kaiapó, os Timbira e os Xerente. Ainda segundo esse autor, "devido a um decréscimo populacional e às uniões recorrentes com regionais, os Karajá do Norte passaram por mudanças culturais importantes" (ALBUQUERQUE, 2013: 145), de modo que, "De acordo como o território onde estão situados, classificam-se também como 'Karajá de cima' (Imbikó Nahandú) e 'Karajá de baixo' (Iranru Nahandú), conforme estejam localizados na parte mais alta do Rio Araguaia" (TAVEIRA, 1982: 27). 
Toral (1992: 35) traz também outras informações sobre a forma de distribuição das aldeias Karajá, tendo em vista a sua localização e processos históricos dos quais se originaram:

(1) os Karajá meridionais, ou seja, ao sul da Ilha do Bananal, (2) os de seu trecho médio, compreendido entre as barras dos rios das Mortes e Tapirapé, e (3) os Karajá "setentrionais", que vivem atualmente ao norte da barra desse último rio até a atual Santana do Araguaia. Estes últimos não devem ser confundidos com os Karajá do Norte.

Os Karajá-Xambioá constituem-se em “um dos três sub-grupos dos Karajá (os demais são os Karajá e os Karajá-Javaé) que habitam as margens do rio Araguaia, ao norte da ilha do Bananal” (GIRALDIN, 2002: 02). O grupo Karajá utiliza, normalmente, a língua portuguesa na sua forma de comunicar e, como segunda língua, o Iny rybè que "tem se restringido principalmente à escola, uma vez que há um número muito pequeno de falantes de Iny rybè, em sua maioria anciãos e anciãs" (NASCIMENTO, 2013: 85). Justificando o autor que os casamentos interétnicos e a língua Iny rybè, restrita ao uso escolar, são causas para o desuso da língua originária (NASCIMENTO, 2013).

As primeiras referências a esse grupo, que circulavam ao longo do rio Araguaia, teriam surgido a partir do século XVII o que justificaria o processo de demarcação, haja vista que a ocupação dessas terras viria de tempos imemoriais (MELO, 1996).

Pelos estudos históricos do grupo apontado no relatório do processo de demarcação, verifica-se que os Xambioá já ocupavam a região, numa área mais vasta ao longo do rio Araguaia e, com o passar do tempo, a terra foi ocupada, também, pelos Karajá e Guarani. Os povos Karajá se subdividiram em Xambioá, Javaé e Karajá propriamente, e ocupavam a região no vale do médio Araguaia, dominando os afluentes como os Rios Tapirapé, das Mortes e Cristalino e na margem esquerda disputava com outras etnias da região como os Xavante, Kayapó e Tapirapé (MELO, 1996).

As histórias de contato entre os Xambioá, Karajá e Jesuítas vindos do Pará datam dos períodos iniciais do século XVII e em seguida com os bandeirantes que ocupavam a região. "Nos séculos XVII e XVIII, as bandeiras paulistas exploraram a região do Araguaia e de seus afluentes à procura de ouro e de mão de obra indígena" (JACOBS, 2000: 17). Segundo Jacobs (2000), os primeiros relatos sobre os Karajá se dão no século XIX: “Fonseca em 1868, Castelneau em 1840 (publica quatro volumes de seu diário de viagens pela América do Sul), e 
Couto de Magalhães em 1863 (publica pela primeira vez sua 'Viagem ao Araguaia' e elabora os primeiros mapas hidrográficos da região)" (JACOBS, 2000: 17). Já para Toral (1992: 34), os registros sobre os Karajá, nesta região, ocorrem em 1775 por parte do governo que inicia uma "política de aproximação pacífica com os grupos Karajá, que se mantinham arredios devido aos reides escravagistas, iniciam-se os registros sobre sua população e número de aldeias".

Os povos indígenas Karajá e Javaé se submeteram à proteção do Governo de Goiás, com o juramento de fidelidade dos Chefes Indígenas ao Rei de Portugal, por volta de 31 de julho de 1775, em troca de proteção contra os povos Xavantes (Acroá) com quem guerreavam. (MELO, 1996).

Segundo Pétesch [...], após submeter-se oficialmente à autoridade do Rei de Portugal em 1775, os Karajá começaram a ser confinados em fortes e colônias fechadas (como em Nova Beira, na Ilha do Bananal) onde supostamente eram civilizados, e eram obrigados a trabalhar. (JACOBS, 2000: 17)

No século XIX, quando vigorava a ênfase na catequese e na civilização, vieram para Goiás os missionários capuchinhos. Entre os missionários que foram designados para os Karajá e Xavante, estava o Frei Segismundo de Taggia; e o Frei Savino de Rimini, para os Karajá-Xambioá. (GIRALDIN, 2002: 08).

O Frei Savino de Rimini foi o nomeado por Couto Magalhães para a missão de aldear os Xambioá. Segundo Giraldin (2002: 09), “entre o assentamento da missão [...] e a primeira aldeia Xambioá, foi instalado o Presídio de São José dos Martírios, que era um posto militar fundado com um número efetivo de quarenta militares para controlar os Karajá-Xambioá”. Melo (1996) aponta que foram criados cerca de sete presídios que formavam a linha do Araguaia: Santa Isabel, Leopoldina, Januária, Santa Maria, Monte Alegre, Jurupensen e São José dos Martírios.

Com a exploração da navegação do Araguaia, os Karajá tiveram contatos com os nãoindígenas, período em que foram fundados colégios na região, como o Colégio Santa Isabel, na cidade de Leopoldina, criado para educar, de acordo com a política do governo, as crianças indígenas. Esse projeto foi um grande fracasso, porque muitos indígenas morreram por moléstia, levando muitos a retornarem para o lugar de origem. (RIBEIRO, 1979: 76). 
O Frei Savino de Rimini criou, na região dos Xambioá, a Colônia Pedra Branca para a catequese dos índios, "sendo que após três anos de fundação já havia casas alinhadas, cafezais, jardim e um pequeno povoado" (MELO, 1996: 94), cujas atividades estavam ligadas "ao fornecimento de lenha e de víveres, os índios faziam parte da mão de obra nos vapores, durante o século XIX” (MELO, 1996: 95). E observa-se que a ocupação das terras Karajá segue um curso do desenvolvimento da economia nacional com a colonização, "em época áurea com a mineração e na época da recessão com o avanço da frente pastoril” (MELO, 1996: 95).

A partir de 1910, com a criação do SPI, há uma ruptura do Estado com a Igreja e passou também a haver um avanço na preservação cultural e regularização de terras. (MELO, 1996). No contexto do SPI, por volta de 1930, a população dos Xambioá, estava reduzida a 8 grupos locais, cuja tendência foi a constituição de pequenos grupos, formados por unidades familiares (TORAL, 1992). Em 1939, ano em que se realizou um censo que registrava "setecentos e noventa e cinco Karajá, seiscentos e cinquenta Javaé e sessenta Xambioá" (RIBEIRO, 1979: 76). Em 1962, estimava-se a quantidade de 1.150 indígenas em 19 aldeias Karajá, 8 aldeias Javaé e 1 aldeia Xambioá (MELO, 1996).

Para Jacobs (2000: 17) muitos indígenas foram dizimados por epidemias e, no período na navegação, o "rio Araguaia era o mais freqüentado, expondo mais ao contato os subgrupos Karajá e Xambioá”.

A partir do final do séc. XIX em diante, os efeitos dos choques com guarnições militares dos "presídios" construídos na região para vigiá-los e garantir a navegação, da repressão promovida por missionários capuchinhos aliados à violenta aparição de epidemias causaram o desmoronamento de sua população e uma mudança na composição dos grupos. Cerca de aproximadamente 2.000 pessoas em 1842 declinam para 1.350 em 1887, 60 (sic.) em 1940 e 40 pessoas em 1959, o número mais baixo que jamais atingiram. (TORAL, 1992: 28)

Nos anos de 1970, a região de Goiás participou do programa desenvolvimentista visando combater a Guerrilha do Araguaia, principalmente na área ocupada pelos Xambioá. Houve grande incentivo para a criação de gado, através dos incentivos fiscais da SUDAM, Banco da Amazônia S.A. e Programa Polamazônia (MELO, 1996). Assim, a região do Araguaia onde estão os Karajá conseguiu viver em "relativa independência, mesmo porque o Araguaia só nos nossos dias seria realmente integrado na economia nacional, através da ocupação dos campos marginais por criadores de gado" (RIBEIRO, 1979: 76). Desta forma, 
nessa região em que se localiza a Terra Indígena Xambioá a pecuária predomina, mas não influenciou os indígenas Karajá que continuam realizando a agricultura familiar dentro da área demarcada.

\section{A DEMARCAÇÃO DA TERRA INDÍGENA XAMBIOÁ}

A Terra Indígena Xambioá1 está dividida em quatro aldeias: “Aldeia Xambioá, Aldeia Kurehê, Aldeia WaryLỹtỹ e Aldeia Hawa Tamara, em soma possuem população de 593 habitantes" (GOMES, 2016: 01) e estão localizadas na região do baixo Araguaia, à margem direita do rio, cujo grupo indígena fala um dialeto específico da língua Karajá, pertencente ao tronco Macro-Jê (MELO, 1996). A Terra Indígena Xambioá iniciou o seu processo demarcatório ainda no período do SPI, por meio do Chefe da $8^{\circ}$ Inspetoria Regional do SPI, Sr. Iridiano Amarinho de Oliveira, que, segundo o processo de demarcação da referida Terra Indígena, no dia 10 de novembro de 1961, compareceu no Departamento de Terra e Colonização do IDAGO, com duas testemunhas declarando que no dia 30.07 .60 requereu a área para os índios Karajá, conforme Despacho Governamental n 2.361 do Processo $\mathrm{N}^{\circ} 1.1$ 00287/59 (FUNAI, 1990).

Pela Certidão do Instituto de Desenvolvimento Agrário de Goiás (IDAGO), consta que a área de ${ }^{\circ} 13$, do Loteamento Rio Lontra e Andorinhas, município de Filadélfia, adquirida por doação do Estado de Goiás, foi homologada por Despacho Governamental sendo a área transferida com Título de Domínio ao SPI para a "Aldeia Carajá", com medição inicial de 3.537,50ha (FUNAI, 1990)

Nesse período, os governos estaduais mantinham o controle das terras devolutas permitido pela Constituição da República de 1891. "Como essa Constituição foi omissa a respeito das terras dos índios, era através da concessão estadual de terras devolutas que os inspetores do SPI garantiam posses aos índios" (OLIVEIRA \& FREIRE, 2006: 119), embora a demarcação de terras tenha ficado como encargo do SPI, órgão federal, nos termos do Decreto $8.072\left(\operatorname{artigos} 4^{\circ}, 5^{\circ}\right.$ e $\left.6^{\circ}\right)$ (BRASIL, 1910).

\footnotetext{
${ }^{1}$ Para falar dos Karajá do Norte, nesse artigo, estamos privilegiando o uso da expressão Terra Indígena Xambioá por ser mais atual e condizente com os dados da FUNAI, mas muitos estudiosos ainda usam Terra Indígena e aldeia como termos similares. Para a FUNAI, a aldeia constitui hoje o lugar dos "vários assentamentos existentes em uma Terra Indígena" (CAVALCANTE, 2016: 23).
} 
Mesmo após a Constituição de 1934 ter garantido a posse da terra aos indígenas, os estados federados tratavam as terras indígenas como devolutas, sendo esta questão resolvida apenas com o Estatuto do Índio em 1973. Situação que ocorreu com a Terra Indígena Xambioá, que iniciou a demarcação pelo SPI, perante o Insituto de Desenvolvimento Agrário de Goiás (IDAGO), cuja aldeia era localizada no Município de Filadélfia, ainda Estado do Goiás, em 30 de março de 1963. Posteriormente, o terreno passaria para o Município de Araguaína, Estado do Tocantins. O termo dado como título de domínio foi assinado pelo Inspetor, Governador do Estado, pelo Secretário de Estado da Agricultura, Indústria e Comércio. "O Título do Imóvel foi registrado no Cartório do $1^{\circ}$ Oficio e Registro de Imóvel Anexos na comarca e município de Araguaína, no dia 30 de março de 1963, foi transcrito sob o n 1.576, fls. 96-97 do livro 3-D de Transcrição das Transmissões" (MELO, 1996: 98). Extinto o SPI, essa área indígena Xambioá, teve seu processo continuado pela FUNAI, que passou a gerenciar a política indigenista a partir de 1967.

A demarcação seguia os trâmites do Decreto 76.999, de 08 de janeiro de 1976, para o reconhecimento prévio da área a ser demarcada, o qual estabelecia que: a) O Presidente da Fundação Nacional do Índio (FUNAI) nomear um antropólogo e um engenheiro ou agrimensor, incumbidos do reconhecimento prévio da área; b) Edital com os termos da demarcação, visando tão somente ao conhecimento, pelos confinantes, de sua realização; c) Relatório pelo grupo de trabalho contendo a descrição dos limites da área, atendidos a situação atual e o consenso histórico sobre a antiguidade da ocupação dos índios; d) O relatório deverá ser aprovado pelo Presidente da FUNAI que fará a demarcação nos ermos do mesmo; e) Homologação do Presidente da República; f) A demarcação deveria ser registrada em livro próprio do Serviço do Patrimônio da União (SPU) e no Livro do Cartório imobiliário da comarca da situação das terras. (BRASIL, 1976).

Desta forma, dando cumprimento ao artigo $5^{\circ}$ do Decreto 76.999 , no dia 24 de maio de 1978, o presidente da FUNAI expediu Edital tornando pública a demarcação administrativa da área indígena denominada Posto Indígena Xambioá ${ }^{2}$ localizado no município de Araguaína, conforme a delimitação proposta anexa aos autos, informando ser a área com os

\footnotetext{
2 A área a ser demarcada é denominada nos autos de demarcação nº 08620.002350/1990-09como Posto Indígena Xambioá, pois iniciada sob a atuação do SPI. Ao final do processo, com a homologação, o Decreto Presidencial de 03 de novembro de 1997 trata a área de Terra Indígena Xambioá (FUNAI, 1990: 142), inclusive publicada a Portaria $n^{\circ} 1060$, de 05 de dezembro de 1994, pelo Presidente da FUNAI, determinando que todo e qualquer território indígena criado e/ou a ser criado terá categoria de TERRA INDÍGENA, retroagindo seus efeitos a partir de 05 de fevereiro de 1991. (FUNAI, 1990: 130).
} 
mesmos limites onde já funcionava o posto indígena, cuja demarcação não há registro, nem homologação anterior (FUNAI, 1990: 10). Com esta publicação, tornou-se possível a contestação da área por possíveis ocupantes, vizinhos ou demais interessados.

Durante o trâmite do processo para regularizar a situação da Terra Indígena, a análise fundiária da demarcação foi realizada por uma firma contratada por licitação com ampla concorrência, a Patraty Topografia S/C Ltda, cujo trabalho não foi conclusivo deixando margem de dúvidas. Uma equipe da FUNAI também procedeu à medição, não sendo o trabalho conclusivo; portanto, a controvérsia nos autos ficou em torno da área a ser demarcada, uma vez que constava no registro solicitado pelo SPI uma área de 3.537,50ha (FUNAI, 1990: 58).

No levantamento fundiário da terra, não está descrito no processo quais os critérios, entrevistas, narrativas, foram utilizados para se fixar a quantidade de terra, nem para se fazer os limites geográficos. A empresa licitada apresentou os limites demarcatórios a partir da demarcação que havia no registro cartorário do Posto Indígena Xambioá, tendo sido fixado em um dos lados confrontantes o rio Araguaia, importante para a mitologia Karajá, de outro, as matas e as circunvizinhas fazendas de gado. Após as devidas formalidades, com a informação de não habitar na terra nenhuma família de não índios, a área foi medida com as dimensões de 3.326,3502 ha, verificando-se uma diferença de 272,50000 ha, porém, não consta no processo $\mathrm{n}^{\mathrm{o}}$ 08620.002350/1990-09 conflitos ou contestações de pessoa confrontante da terra sobre a medição da demarcação.

A superfície da Terra Indígena Xambioá registrada no CRI, é maior que aquela aviventada $(3.537,5000$ ha/ 3.265,0000), apontando que diferença de 272,50000, que decorre da adequação de mapas no período de 1963 a 1991, bem como mudanças das praias e curso do rio Araguaia. Vale lembrar que esta discrepância encontra-se dentro da faixa tolerada, menos de $10 \%$ (dez por cento), que é um processo usualmente na Cartografia. (MELO, 1996: 101).

Para a conclusão do processo, foi apresentado relatório antropológico pela antropóloga Maria Guiomar de Melo, exigido pelas normas, com contexto histórico, para comprovar a ocupação da terra pelos indígenas desde tempos imemoriais, através de fontes ou documentos históricos. A antropóloga foi nomeada pelo Chefe do Serviço de Identificação e Delimitação da FUNAI para proceder aos estudos. A pesquisadora se baseou em bibliografia de antropólogos, indigenistas, e outros estudiosos que atuaram na região, para elaborar relatório 
que foi anexado ao processo de demarcação da Terra Indígena Xambioá. Tais estudos, segundo informações dos bandeirantes, missionários, funcionários do Estado, indicam que a região sempre foi ocupada por indígenas Xambioá ao longo do Rio Araguaia e com o passar do tempo, as etnias Karajá e Guarani também passaram a habitar a terra (MELO, 1996).

Para elaborar o Parecer, contudo, a antropóloga não realizou entrevistas ou visitou o local. Estabeleceu o estudo pelas pesquisas já realizadas na região ou pelo próprio Posto Indígena Xambioá, concluindo favoravelmente à demarcação e sua homologação. É importante ressaltar que, no processo demarcatório, a equipe técnica, ao fazer o levantamento do espaço necessário ao grupo no procedimento de identificação e delimitação, "não se limita a levantar os espaços necessários para a habitação e reprodução econômica de um povo, mas também inclui aqueles locais de relevância para a sua cultura, religião e organização social" (CAVACANTE, 2016: 05-06).

Apesar de constar nos encaminhamentos para o relatório antropológico e no próprio relatório sobre a imemoralidade do grupo Karajá na terra, os memorandos de 1996, expedidos pela FUNAI, constatam que a terra "era ocupada tradicionalmente pelos índios Xambioá, Guarani e Karajá" (FUNAI, 1990: 134). Situação essa que se pode concluir que a Terra Indígena Xambioá teve sua tradicionalidade reconhecida após a Constituição de 1988, com a área transferida para o SPI pelo IDAGO em 10 de janeiro de 1961, sendo "territorialmente definida desde 1960" (TORAL, 1992: 30).

O procedimento de demarcação da Terra Indígena Xambioá (kabiruru), etnia Karajá, já iniciado pelo SPI, foi regularizado pela FUNAI, através do Ministério da Justiça, em 27 de novembro de 1990, sob o $\mathrm{n}^{\circ}$ 08620-2350/90 e depois de submetido à homologação, ocorrida em 03 de novembro de 1997, pelo Ministro da Justiça, através da publicação de Decreto assinado pelo então Presidente da República, Fernando Henrique Cardoso, com 3.326, 3502 ha (três mil, trezentos e vinte e seis hectares, trinta e cinco ares e dois centiares), de acordo com a Lei ${ }^{\circ}$ 6001/ 73 e Decreto ${ }^{\circ}$ 1775/96.

Com afirma Certeau (2008), a demarcação permite a distribuição do espaço. A operação para realizar a demarcação, as narrativas e os relatos "são compostas com fragmentos tirados de histórias anteriores e 'bricolados' num todo único”. A terra, que tinha uma concepção de lugar coexistindo de forma estável e única com a ocupação do grupo, passa a ser espacializada (CERTEAU, 2008: 208-215), permitindo a demarcação, tornando a terra de uso exclusivo do grupo. 
Em 2002, foi realizada, pela FUNAI e lideranças indígenas, a aviventação dos marcos da terra dos Karajá do Norte, com a localização de todos os marcos de concreto das demarcações pretéritas, cuja ata da reunião constata que "toda a comunidade tem pleno conhecimento dos limites da área, sendo que parte já se encontra cercada; restando apenas 12 $\mathrm{km}$ em aberto, mas, quase todos conhecem pois é área de caça da comunidade" (FUNAI, 1990: 151). Neste procedimento de aviventação, não houve contestação dos marcos demarcatórios, sendo constatado que a comunidade indígena ficou satisfeita com os trabalhos (FUNAI, 1990: 151).

A demarcação, portanto, atende ao Poder Público, no aspecto normativo-jurídico, para tornarem públicas e estáveis as relações entre governo, indígenas e não-indígenas. Por sua vez, para a comunidade indígena, a demarcação propicia um lugar de habitação, de sobrevivência, de trabalho, de prática das tradições, acostuma-se a fixar numa área determinada e tem reconhecimento público como indígena.

\section{TERRITORIALIDADE INDÍGENA DOS KARAJÁ DO NORTE}

A territorialidade indígena possui várias facetas, dependendo da perspectiva a ser abordada. Como diz Haesbaert (2007: 22), a territorialidade está "intimamente ligada ao modo como as pessoas utilizam a terra, como elas próprias se organizam no espaço e como elas dão significado ao lugar”. Assim, a territorialidade é tomada enquanto componente do poder - e não apenas um modo para estabelecer e manter a ordem -, mas uma estratégia para criar e manter grande parte do contexto geográfico (por meio do qual nós experimentamos o mundo e o dotamos de significado (HAESBART, 2007).

A territorialidade do povo Karajá é uma construção histórica de povos que se servem do Rio Araguaia e dos seus ciclos, ocupando, usando, mantendo as tradições, defendendo a terra e convertendo-a, assim, em seu "território", delimitando assim sua área de abrangência e permitindo a identificação com o local. A organização do povo Karajá, no Tocantins tem seu arranjo espacial histórico no Norte do país desde 1872 (KARASCH, 1992: 409). É representada como uma tribo bravia, que trabalhava ajudando a navegação com o fornecimento de madeira para os barcos a vapor, se utilizando da longa área na extensão do rio Araguaia, cujo ritmo de vida foi influenciado pelos ciclos do rio e estações do ano - entre pescar na praia, durante as secas do rio, e cuidar das plantações, nos períodos de chuva. 
A trajetória do povo Karajá teve influência do bandeirante, dos mineradores de ouro, "traficantes, militares e missionários que se haviam estabelecido nas nascentes do Araguaia e procuravam uma saída para o oceano" (RIBEIRO, 1979: 75). Os índios Karajá e Guarani têm no Rio Araguaia a sua fonte principal de vida, inclusive da mitologia, dos costumes, e habitação com aldeias próximas ao rio para facilitar o trabalho com a pesca. Inclusive, Taveira (1982, p. 27), em estudo etnográfico realizado sobre os Karajá, localizados em Santa Izabel do Morro, narra que "são um povo que primeiramente vivia na mata. Exterminados estes vieram aqueles que viviam debaixo das águas, onde ainda hoje existem Karajá”.

Os Karaja habitavam as profundezas, "Lá eles eram imortais, lá não havia problemas de alimentação" (TORAL, 1992: 145). Saindo para a superfície por buracos, tendo especificamente, os karajá saído no local onde está situado o Rio Araguaia, conhecido como "Inysèdyna", significando "lugar de onde veio a mãe da gente" nas proximidades do norte da Ilha do Bananal (TORAL, 1992: 145). Há, ainda, outros Karajá que "saíram em outros locais ao longo desse mesmo rio" (TORAL, 1992: 145). De tal forma que, na mitologia Karajá, eles saíram do inframundo e aqui se estabeleceram, e "não se sentem de forma alguma isolados em sua existência aqui na superfície da terra" (TORAL, 1992: 147). Os Karajá subaquáticos, ao quererem conhecer a superfície, "descobriram os vastos espaços e a morte. Assim, ao emergir, alguns moradores das profundezas aquáticas se tornaram humanos de verdade, inÿ tyhy (gente de verdade)" (JACOBS, 2000: 26).

Os costumes e a mitologia, segundo Melo (1996), são cultivados pelos indígenas, que consideram o rio sua fonte de vida, bem como tratam a vida humana como sendo subaquática, entre meio homem e meio peixe, seria um ser mutante, estando o mundo dividido em três níveis e em três povos: 1) bede rahy mahadu é o povo do fundo das águas; 2) bede mahadu iny tyhy é o povo da terra, os homens verdadeiros; 3) bede mahadu é o povo da chuva. (JACOBS, 2000: 26).

O povo Karajá "concorda em dizer que, nos mundos aquático e celeste, as aldeias são idênticas às aldeias Karajá da superfície, a única diferença é que as aldeias subaquáticas e celestes são melhores, mais bonitas e duradouras" (JACOBS, 2000: 37). A ligação com o mundo aquático está marcada também pelas festividades dos Karajá, “a Festa do Índio, que habitualmente acontece no mês de abril, a Festa do Peixe, no mês junho e a Festa da Tartaruga, no mês de julho" (GOMES, 2016: 01). 
Pela proximidade com o Rio Araguaia, no período do verão na região Norte, os grupos Karajá têm o costume de usufruir das praias arenosas, em que "as aldeias maiores simplesmente se transferiam para as praias e os habitantes das menores se separavam numa série de pequenos grupos, que exploravam, com grande mobilidade, as praias próximas às suas aldeias de inverno" (TORAL, 1992: 103).

Por viverem às margens das águas do rio, os Karajá têm a prática da natação, sabem remar e são bons pescadores. Sobrevivem da pescaria no verão e dominam o uso de arco e flecha e do arpão (MELO, 1996). Assim, no verão, a partir de 1960, as mulheres habitam as casas enquanto os homens cuidam da pesca (TORAL, 1992). O rio é considerado parte das aldeias Karajá, pelos hábitos e tradições que cultivam a partir de suas águas, sendo usado como um "porto para as canoas, nele se banham as famílias de manhã e à tarde, as mulheres lavam as roupas e a louça e, de suas margens retira-se o barro utilizado na confecção de vasilhames e bonecas (ritxokò) de cerâmica" (JACOBS, 2000: 32).

O grupo sobrevive não só da pesca (maio a outubro), mas da prática da caça, agricultura (mandioca, algodão, milho, batata doce, abóbora, inhame, melancia e arroz) e coleta de frutos silvestres. "Durante a seca, andam pelas praias, pescando e colhendo ovos de tartarugas, fundamentais em sua alimentação. Durante o período das chuvas, em decorrência das cheias, migram para o interior, onde se dedicam ao cultivo de roças” (MELO, 1996: 106).

Para explicar a agricultura dentro da comunidade indígena, os Karajá explicam que os humanos sabiam "caçar, plantar roças, andar de canoa" (JACOBS, 2000: 30) e que, com a mudança dos Karajá aquáticos em seres humanos quando emergiram das águas, tiveram que aprender tais atividades:

Antes da chegada dos Inÿ Tyhy (i.e. da transformação dos KARAJÁ subaquáticos em gente de verdade, KARAJÁ terrestres), na superfície viviam os Ixÿ (termo que designa todo ser vivo apegado a um território), a antiga humanidade terrestre. Os Ixÿ eram animais humanos que, na maioria dos casos, foram sendo transformados pelos heróis míticos (principalmente por Kanÿxiwe) em verdadeiros animais ou em estrangeiros (Ixÿju, vizinhos e inimigos dos Karajá). O que distinguia os Ixÿ dos Inÿ Tyhy em seus modos de vida era a capacidade de mobilidade dos primeiros. Os Ixÿ sabiam caçar, plantar roças, andar de canoa [...]. Para se adaptar à nova vida, os KARAJÁ tiveram de adquirir ao menos uma parte dessa mobilidade terrestre. (JACOBS, 2000: 30).

Assim, caçam pouco, pela fartura do rio, e se dedicam mais às atividades agrícolas, como a plantação de mandioca, do "algodão, o milho, a batata doce, a abóbora, o inhame, a 
melancia, o arroz. Complementam sua dieta com frutas silvestres" (MELO, 1996: 115). Os Karajá-Xambioá praticam a pesca de peixes, de tartaruga, entre outros, mas poucos são os que utilizam arco e flecha para as atividades de captura, partindo para as pescas predatórias por alguns índios e mesmo não-índios, ocasionando escassez de certas espécies aquáticas. "A pesca tem, assim, se tornado mais difícil, e a necessidade de se distanciar das aldeias para encontrar os peixes e as tartarugas é cada vez maior. O impacto das mudanças atingiu ainda outras formas de produção de alimentos" (NASCIMENTO, 2013: 87).

Atualmente, o consumo de produtos industrializados, como açúcar, óleo, feijão, arroz, sal, interferiu na alimentação dos Xambioá-Karajá. “A prática de cultivo de roças para plantação de víveres que faz em parte dos hábitos alimentares tradicionais do povo Karajá Xambioá também se tornou obsoleta, quase desaparecendo completamente ao longo das décadas” (NASCIMENTO, 2013: 87-88). Foi a partir da década de 1960, que as práticas culturais Karajá-Xambioá entram em decadência com a diminuição de produção de peças artesanais, pinturas no corpo, cuja justificativa era a vergonha da população jovem ser vista nos municípios próximos "pintados/as ou caracterizados/as como índios/as" (NASCIMENTO, 2013: 87).

As aldeias refletem a organização social e política da comunidade. Na Terra Indígena Xambioá as aldeias mais antigas, Xambioá e Kurehê estão "localizadas próximo ao rio Araguaia. As outras que foram constituídas posteriormente, por questões de política interna ao grupo, estão mais afastadas. Cada aldeia tem seu espaço para caça, pesca e práticas de rituais” (FLORES, 2016, p. 44). Os indígenas passam a maior parte do seu tempo em convívio coletivo nas aldeias; as construções são feitas, geralmente, atendendo à proximidade ao Araguaia. Sendo as aldeias compostas por "uma fileira de casas alinhadas e paralelas à margem do rio, em geral em cima de altas barreiras. Isso faz com que durante a maior parte do ano tenha-se que descer e subir alguns metros para se alcançar os portos, as canoas, buscar água, etc.” (TORAL, 1992: 63).

As construções atuais são feitas de tijolos e cimento, com cobertura de telha; no entanto, a varanda de entrada das casas mantém a forma oval e a cobertura de palha, procurando manter os traços das antigas construções. A maioria das casas já não usa mais as estruturas de madeiras, cobertas muitas vezes por esteiras, ou construções de palha.

Não é por acaso que a territorialidade do grupo Karajá está envolta com curso do rio Araguaia, mesmo tendo se deslocado ao longo do rio por pressões advindas das missões, das 
lutas por terras, a reação à instalação dos postos indígenas pelos órgãos federais. Ali encontraram um espaço para desenvolverem suas tradicionalidades e a riqueza de suas mitologias.

Dessa forma, os Karajá estabeleceram a sua territorialidade a partir do lugar onde viviam, da paisagem, dos recursos naturais, da localização da terra e do contexto histórico envolvido.

Figura 2 - Rio Araguaia compondo a paisagem da Terra Indígena Xambioá

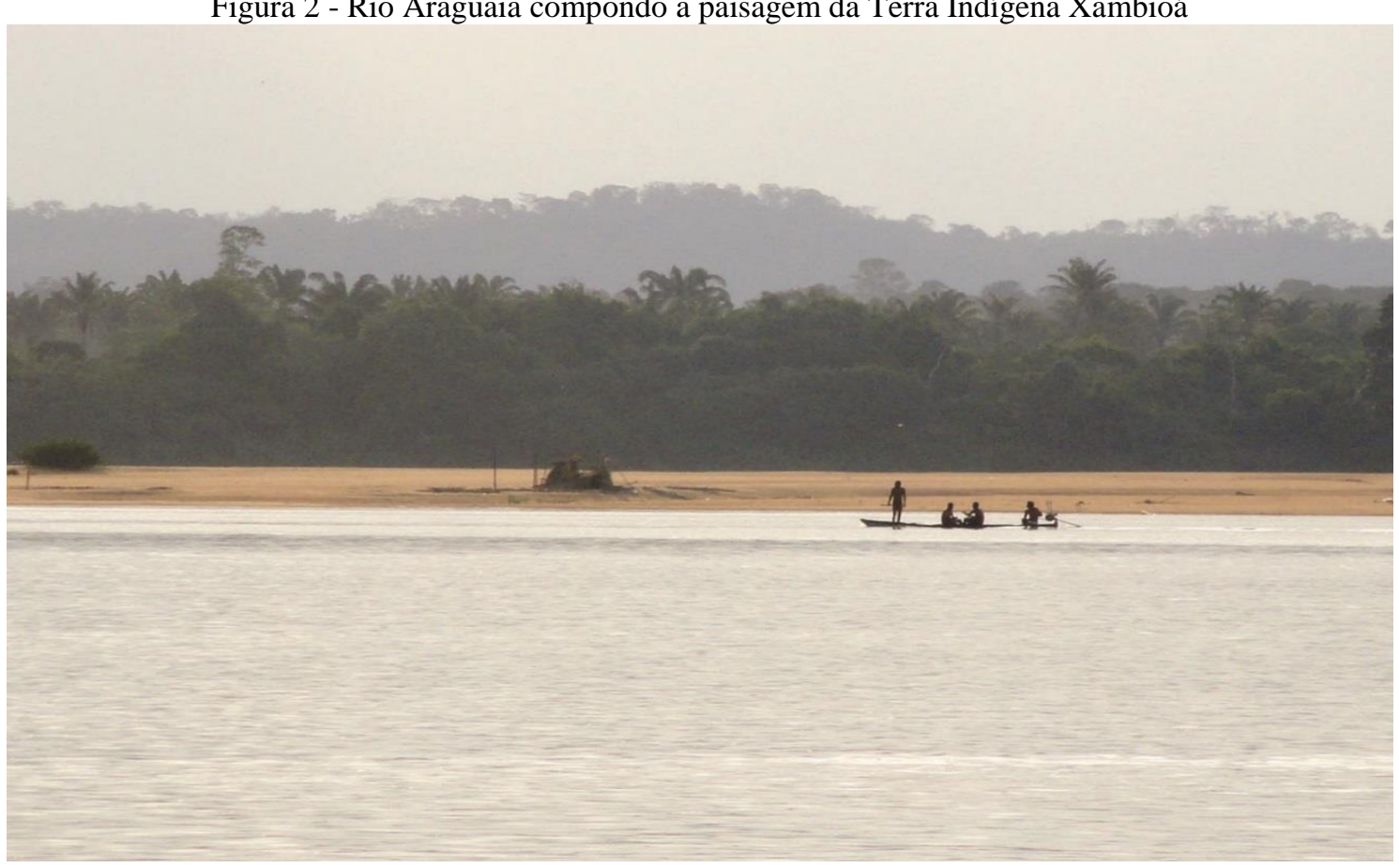

Fonte: (FLORES et. al., 2016, p. 47).

O rio Araguaia, importante na mitologia e na construção da territorialidade Karajá, explana uma paisagem natural, preservada, que coloca a Terra Indígena Xambioá numa região privilegiada, visto que o rio é cobiçado pelas elites locais, nas temporadas de estiagem com a formação de ilhas e praias arenosas de água doce. Assim, o rio Araguaia, pela intensa ocupação, valorização e atrativos culturais que oferece no mês de julho, é palco cultural da região, possuindo significados diversos, revalorizados, inclusive pelas elites das regiões pelos quais o rio faz seu percurso, é uma paisagem ${ }^{3}$ "mercantilizada e transformadas em novas territorialidades das elites urbanas" (LUCHIARI, 2001: 10). Por outro lado, a paisagem das

\footnotetext{
${ }^{3}$ A paisagem analisada pelo indivíduo "é forma e aparência. Seu verdadeiro conteúdo só se revela por meio das funções sociais que lhe são constantemente atribuídas no desenrolar da história” (LUCHIARI, 2001: 13).
} 
águas do rio Araguaia para os indígenas é carregada de simbolismo, da mitologia Karajá e determina a demarcação de fronteira territorial.

Os Karajá, embora tenham a terra definida com limites geográficos, demarcada, e convivam pacificamente com vizinhos não índios, ainda enfrentam problemas como: a) Por estarem inseridos em área da Amazônia Legal, sofrem com o avanço do desmatamento e com focos de incêndio ${ }^{4}$; b) Fazendas vizinhas desmatam e queimam em volta da Terra Indígena para a manutenção de suas pastagens, afetando as florestas; c) Desmatamento afetando as margens do rio Araguaia, provocando o assoreamento no período chuvoso; d) Pescadores e caçadores invadem a Terra Indígena para a coleta, inclusive, de Tartarugas-da-Amazônia em época de desova; e) Ocorrem constantes invasões de gado, pela proximidade com fazendas vizinhas com atividades de pecuária ${ }^{5}$ (FLORES, 2016: 44).

Como os grupos sociais que ocupam determinado espaço possuem necessidades diferentes, a territorialidade desses grupos sofre variação. Por um lado, temos uma visão hegemônica de territorialidade que se relaciona à sociedade capitalista e orienta as ações do Estado no mundo ocidental desde o início do período moderno. Por outro, temos uma territorialidade dos povos tradicionais que estabelecem relações próprias, conforme suas tradições, necessidades e experiências, com o lugar onde habitam.

A cultura dos indígenas estabelece a posse comunitária de terras, sem os tornar donos e, ao mesmo tempo, estipula a proteção aos usos, tradições e costumes indígenas, com a preservação da cultura, devendo, dentro da terra, ser respeitada a forma de propriedade indígena. No entanto, o próprio estatuto indígena estabelece uma política de integração do indígena à comunhão nacional e o governo federal traça políticas públicas voltadas para essas comunidades criando condições para que o índio venha a se tornar um camponês, um lavrador.

Assim, o Projeto de Gestão Ambiental e Territorial Indígena (GATI), executado pela FUNAI, em parcerias com organizações indígenas e outros órgãos, implantou na Terra Indígena Xambioá, no ano de 2013, oficinas para promover o incentivo ao manejo e criação de Tartarugas-da-Amazônia; capacitou os indígenas na apicultura para produção de mel, com o objetivo de utilizarem o mel na alimentação e como gerador de renda pela sua

\footnotetext{
${ }^{4}$ Terra Indígena Xambioá

${ }^{5}$ Disponível em: <http://cggamgati.FUNAI.gov.br/index.php/experiencias-em-gestao/terra-indigena-x/>. Acesso em: 02 abr. 2017.
} 
comercialização; aprimorou o cultivo de roças tradicionais e roças de fundo de quintal (FLORES, 2016).

O trabalho rural é um traço característico das comunidades indígenas. Para Oliveira (1998: 20), existe uma diferença entre o campesinato indígena em relação a outras formas de campesinato para quem o labor rural indígena tem o "controle coletivo sobre o meio básico de produção, há que ser destacado que tal campesinato é, por diversos meios, colocado como sendo diretamente subordinado ao Estado". Destacamos, ainda, que o Estado, no seu processo de territorialização, estabelece um paternalismo em relação ao indígena tornando-o subordinado, nos seguintes aspectos apontados por Oliveira (1998): a) O índio tem uma capacidade relativa, sendo tutelado pela União, através da FUNAI (at. $7^{\circ}, \S 2^{\circ}$, Estatuto do Índio); b) As terras indígenas são de propriedade da União, não tendo as comunidades indígenas a plena propriedade, somente a posse e usufruto das áreas em que habitam; c) as modalidades de terras indígenas previstas no Estatuto do Índio, “incluídas aquelas de domínio indígena - são consideradas como bens do Patrimônio Indígena" (art. 39) ficando a gestão de tais recursos a cargo do órgão federal de assistência, a FUNAI (art. 42)" (OLIVEIRA, 1998: 20).

Para Almeida (2013: 255), as diversas comunidades étnicas, ao se reunirem em aldeia, iniciam o processo de territorialização, "isto é, passavam a habitar um território fixo que lhes fora dado ou até imposto, conforme as circunstâncias, por uma ordem político-administrativa externa ao grupo". Assim, esse modelo de territorialização, imposto pelo Estado desde a época colonial, encadeou mudanças culturais nas várias etnias reunidas num mesmo espaço social que, "na experiência comum do cotidiano, reconstruíram culturas, valores e tradições, misturando-se entre si e com outros grupos sociais" que, a partir desses fatos, acabaram "ressocializando-se e recriando culturas e identidades" (ALMEIDA, 2013: 256). É importante destacar, porém, que nesse contato houve uma resignificação tanto na cultura dos povos indígenas quanto na dos não-indígenas. Não à toa, o hibridismo cultural, resultante da convivência de vários grupos étnicos num mesmo território, é uma das características marcantes da sociedade brasileira. 


\section{CONSIDERAÇÕES FINAIS}

A territorialização imposta aos indígenas pelo Estado Brasileiro ao longo da história interfere diretamente no exercício da territorialidade desses grupos. Na etnia Karajá, residente no atual Estado do Tocantins, há uma nítida identificação com a água, fazendo com que esse grupo procurasse sempre manter a proximidade com o rio. Mas as políticas indigenistas, sobretudo a partir do século XIX, não os permitiram exercer plenamente suas territorialidades, na medida em que buscaram construir presídios nas margens dos rios Araguaia e Tocantins para incentivar o desenvolvimento econômico desses espaços.

Embora o governo, desde 1910, tenha criado normas jurídicas para a demarcação de terras, é interessante observar que, apesar dos estudos antropológicos apontarem essa relação intrínseca dos Karajá (e outros indígenas) com o local onde vivem, o burocrático e moroso processo de demarcação e delimitação da área da aldeia destinada aos povos indígenas, mesmo quando homologado, não os torna proprietários da terra que se transformam em patrimônio público da União.

Ainda que o processo de demarcação possa acontecer após a identificação da área como de ocupação tradicional, o Estado brasileiro tem dificuldades em reconhecer os territórios sociais dos povos tradicionais dentro do Estado-nação (LITTLE, 2002). A exemplo disto, o próprio requerimento da Comissão Parlamentar de Inquérito (CPI, 2015) nº 16/2015 questiona os critérios utilizados nas demarcações, as nuances dos conflitos sociais e toma o processo administrativo de demarcação como arbitrário, baseado em laudo técnico ideologizado, com potencial para revogar registros públicos, cuja questão fundiária, apontada no pedido de CPI, alega que $14 \%$ do território brasileiro está destinado a terras indígenas, sendo a população indígena 0,30\% do total da população nacional (CPI, 2017).

O fato é que o Estado e o poder privado têm ignorado a questão da territorialidade indígena, tentando impor um projeto que visa a criação de uma identidade nacional em detrimento das identidades dos vários grupos indígenas existentes no Brasil. Para a preservação dessas identidades indígenas é fundamental a demarcação de terras, contudo, o sistema jurídico moroso ainda gera muitas dificuldades para que o direito desses povos originários seja efetivado e respeitado. 


\section{REFERÊNCIAS}

ALBUQUERQUE, Francisco Edviges. 2013. "Índios do Tocantins: aspectos históricos e culturais". In: SILVA, Norma Lucia da; VIEIRA, Martha Victor. (Org.). Ensino de história e formação continuada: teorias, metodologias e práticas? Goiânia: Ed. da PUC Goiás, pp. 135158.

ALMEIDA, Maria Regina C. 2013. Metamorfoses indigenas: identidade e cultura nas aldeias coloniais do Rio de Janeiro. $2^{\mathrm{a}}$ ed. Rio de Janeiro, Editora FGV.

ATA DO CONSELHO GERAL DA PROVÍNCIA DE GOIÁS. 1832. In. A Matutina Meiapontense, Meiaponte, $\mathrm{n}^{\circ}$ 340, pp. 1-2.

BRASIL. Câmara dos Deputados. 2017. Relatório Final CPI FUNAI e INCRA 2. Disponível em: <http://www.camara.gov.br/proposicoesWeb/prop_mostrarintegra?codteor=1551365>. (Acessado em 10 de julho de 2017).

BRASIL. Constituição da República Federativa do Brasil de 1988. Brasília, DF, 5 out. 1988. Disponível em: <http://www.planalto.gov.br/ccivil_03/constituicao/constituicao.htm>. (Acessado em 7 de outubro de 2016).

Decreto $\mathrm{n}^{0} 1.775$, de 8 de janeiro de 1996. Dispõe sobre o procedimento administrativo de demarcação das terras indígenas e dá outras providências. Diário Oficial [da] República Federativa do Brasil, Poder Executivo, Brasília, DF, 8 jan. 1996. Disponível em: < http://www.planalto.gov.br/ccivil_03/decreto/D1775.htm>. (Acessado em 7 de outubro de 2016).

Decreto $\mathrm{n}^{\circ} 76.999$, de 8 de janeiro de 1976. Dispõe sobre o processo administrativo de demarcação das terras indígenas e dá outras providências. Diário Oficial [da] República Federativa do Brasil, Poder Executivo, Brasília, 1976. Disponível em: < http://www2.camara.leg.br/legin/fed/decret/1970-1979/decreto-76999-8-janeiro-1976425608-publicacaooriginal-1-pe.htmll>. (Acessado em 07 de maio de 2017).

Decreto $\mathrm{n}^{0}$ 8.072, de 20 de junho de 1910. Cria o Serviço de Proteção ao Índio e Localização dos Trabalhadores Nacionais e aprova o respectivo regulamento. Diário Oficial [da] República Federativa do Brasil, Poder Executivo, Rio de Janeiro, RJ, 26 jun. 1910. Disponível em: < http://www.planalto.gov.br/ccivil_03/decreto/D1775.htm>. (Acessado em 7 de outubro de 2016).

Lei $\mathrm{n}^{\circ}$ 6.001, de 19 de dezembro de 1973. Dispõe sobre o Estatuto do Índio. Diário Oficial [da] República Federativa do Brasil, Poder Executivo, Brasília, DF, 19 dez. 1973. Disponível em: <http://www.planalto.gov.br/ccivil_03/leis/L6001.htm>. (Acessado em 7 de outubro de 2016). 
CAVALCANTE, Thiago Leandro. 2016. "Terra indígena: aspectos históricos da construção e aplicação de um conceito jurídico". História, 35. In: http://www.scielo.br/pdf/his/v35/01019074-his-35-00075.pdf. (Acessado em 20 de março de 2017).

CERTEAU, Michel de. 2008. A invenção do cotidiano: 1. Artes de fazer. 14a ed. Petrópolis, Vozes.

FLORES, Lucio Paiva; MACIEL, Márcia Regina Antunes; ALMEIDA, Soraia Campos. Núcleo Regional Amazônia Cerrado. 2016. A experiência do projeto GATI em Terras Indígenas.

Brasília:IEB.In:http://cggamgati.FUNAI.gov.br/files/1814/8837/9954/Ncleo_Regional_Amaz onia_Cerrado.pdf. (Acessado em 13 de julho de 2017).

FRANÇA, A. A. O. 2016. Terras Indígenas do Tocantins. (Elaboração própria).

FUNAI. Modalidades de Terras Indígenas. s/d. In: http://www.funai.gov.br/index.php/indiosno-brasil/terras-indigenas. (Acessado em 05 de outubro de 2016).

. O Brasil Indígena (IBGE). 2016. In: http://www.funai.gov.br/index.php/indios-nobrasil/o-brasil-indigena-ibge. (Acessado em 05 de outubro de 2016).

FUNAI. 1990. Processo de Demarcação no 08620.002350/1990-09. Brasília, DF: FUNAI.

. Terras indígenas. 2017. In: http://www.funai.gov.br/index.php/indios-nobrasil/terras-indigenas. (Acessado em 06 de novembro de. 2017).

GIRALDIN, Odair. "Catequese e Civilização. Os Capuchinhos "entre" os "Selvagens" do Araguaia e Tocantins". 2002. Boletim Museu. Paraense - Emílio Goeldi, Belém, 18 (2). (Série Antropologia). In: http://uft.edu.br/neai/file/odair_catequese_civilizacao.pdf. (Acessado em 12 de janeiro de 2017).

"Povos Indígenas e não indígenas: uma introdução às relações inter-étnicas no Tocantins". 2002. In. GIRALDIN, O. (Org.). A (Trans)formação histórica do Tocantins. Goiânia, UFG, pp. 109-135.

HAESBAERT, Rogério. 2007. "Território e multiterritorialidade: um debate”. GEOgrafia. 9 (17), pp. 19-45. In:

http://www.uff.br/geographia/ojs/index.php/geographia/article/view/213/205. (Acessado em: 20 de janeiro de 2017).

IBGE - Instituto Brasileiro de Geografia e Estatística. 2010. O Brasil indígena (IBGE 2010). In: http://www.FUNAI.gov.br/index.php/indios-no-brasil/o-brasil-indigena-ibge. (Acessado em 05 de outubro de 2016).

2016 Tocantins, Santa Fé do Araguaia. In: http://cidades.ibge.gov.br/xtras/perfil.php?lang=\&codmun=171886\&search=tocantins|santafe-do-araguaia. (Acessado em 13 de dezembro de 2016). 
JACOBS, Lydie Oiara Bonilla. 2000. Reproduzindo-se no mundo dos brancos: estruturas Karajá em Porto Txuiri (Ilha do Bananal - Tocantins). Dissertação de Mestrado em Antropologia Social, Universidade Federal do Rio de Janeiro.

GOMES, Adriano Dias (Karajá). 2016 "Aspectos territoriais e culturais do povo KarajáXambioá". In: ANAIS DO ENCONTRO NACIONAL DE GEÓGRAFOS, A CONSTRUÇÃO DO BRASIL: GEOGRAFIA, AÇÃO POLÍTICA E DEMOCRACIA, 18, 2016. São Luís (MA). São Luís (MA).

KARASCH, Mary. 1992. "Catequese e Cativeiro: política indigenista em Goiás: 1780- 1889”. In: CUNHA, Manuela Carneiro da (Org.). História dos índios no Brasil. São Paulo: Companhia das Letras; Secretaria Municipal de Cultura; FAPESP.

LITTLE, Paul. 2002. Territórios sociais e povos tradicionais no Brasil: por uma antropologia da territorialidade. (Série Antropológica). Brasília. In: http://www.direito.mppr.mp.br/arquivos/File/PaulLittle1.pdf. (Acessado em 10 de agosto de 2016).

LUCHIARI, Maria Tereza Duarte Paes. 2001. “A (re)significação da paisagem no período contemporâneo”. In: ROSENDAHL, Zeny; CORRÊA, Roberto Lobato. (orgs.). Paisagem, imaginário e espaço. Rio de Janeiro, EdUERJ.

MARCONI, Marina de Andrade; PRESOTTO, Zelia Maria Neves. 2015. Antropologia: uma introdução. $7^{\mathrm{a}}$ ed. São Paulo, Atlas.

MELO, Maria Guiomar. 1996. “Terra Indígena Xambioá, histórico”. In: Processo de Demarcação no 08620.002350/1990-09 Brasília, FUNAI, pp. 68-115.

NASCIMENTO, André Marques do. 2013. “Ações para a revitalização linguístico-cultural entre o povo Xambioá: lições desde projetos comunitários”. Tellus, Campo Grande, 13 (25), pp. 83-105.

OLIVEIRA, João Pacheco. "Uma etnologia dos "índios misturados"? Situação colonial, territorialização e fluxos culturais". In: Mana, Rio de Janeiro, v. 4, n. 1, p. 47-77, 1998.

OLIVEIRA, João Pacheco de; ALMEIDA, Alfredo Wagner Berno de. 1988. "Demarcação e reafirmação étnica: um ensaio sobre a FUNAI”. In: OLIVEIRA, João Pacheco de (org). Indigenismo e territorialização: poderes, rotinas $e$ saberes coloniais no Brasil contemporâneo. Rio de janeiro, Contra-capa.

OLIVEIRA, João Pacheco de; FREIRE. Carlos Augusto da Rocha. 2006. A presença indígena na formação do Brasil. Brasília, Ministério da Educação, Secretaria de Educação Continuada, Alfabetização e Diversidade; LACED/Museu Nacional.

RIBEIRO, Darcy. 1979. Os índios e a civilização: a integração das populações indígenas no Brasil moderno. $3^{\text {a }}$ ed. Petrópolis, Vozes.

ROCHA, Leandro. 1998. O Estado e os índios: Goiás - 1850-1889. Goiânia, UFG. 
SILVA, Cleube Alves da. 2010. Confrontando mundos: os povos indígenas Akwen e a conquista de Goiás (1749-1851). Palmas, Nagô.

TAVEIRA, Edna Luísa de Melo. 1982. Etnografia da Cesta Karajá. Goiânia, Ed. da Universidade Federal do Goiás.

TOCANTINS. Lei $n^{o}$ 251, de 20 de fevereiro de 1991. Cria municípios e dá outras providências. Diário Oficial $\mathrm{n}^{\circ}$ 60, Palmas-TO, 20 fev de 1991. In: http://www.al.to.gov.br/arquivo/6509. (Acessado em 26 de janeiro de 2017).

TORAL, André. 1992. Cosmologia e sociedade Karajá. 1992. Dissertação de Mestrado em Antropologia Social, Universidade Federal do Rio de Janeiro. 